\title{
Estudo da Erosão Acelerada na Sub-bacia do Córrego dos Macacos com Ênfase na Erodibilidade do Solo Determinada por Ensaios de Infiltração de Água e de Laboratório.
}

\author{
Luscélia Rodrigues \\ Bolsista de Iniciação Científica - CNPq/PIBIC \\ Aluna do Curso de Geografia - UFU \\ Luiz Nishiyama \\ UFU - Universidade Federal de Uberlândia \\ Departamento de Geografia \\ 38.400-902 - Uberlândia - MG
}

\begin{abstract}
The present study (research) was carried out in the western portion of Uberlandia county comprising the Córrego dos Macacos basin, comprised between the geographical coordenates of $18^{\circ}$ $59^{\prime}$ to $19^{\circ} 02^{\prime}$ Latitude Southern and $48^{\circ} 23^{\prime}$ to $48^{\circ} 35^{\prime}$ Longitude Western of the Greewich Meridian. The principal aim this research was to study the processes responsibles for accelerated erosion of the soil, with emphasis in determination of the erodibility in "in situ" tests and laboratory tests. The metodology emploied constitute of rasing of datas pre-existents; interpretation of aerials photografs in scale 1,25.000; work's field tests. the inconsolidated materials of the study area shown sandy texture and extremely weak; showing high erodibility high values of void raitios and water infiltration; water table at about of 10 meters of depth.
\end{abstract}

Keywords: Soil Erosion; Processes; Inconsolidated Materials

\section{INTRODUÇÃO}

No começo o homem vivia em harmonia com a natureza e esta com o homem. Atualmente esta convivência já não existe mais, pois o homem passou a se organizar em sociedade alterando, assim, todo o meio ambiente (HIDALGO, 1.985). Uma das alterações mais freqüente que o meio ambiente sofre, processa-se via degradação do solo.

A utilização e ocupação do meio físico (solo, rocha, relevo, água e suas relações) pelo homem, condiciona uma série de aspectos destrutivos. A não utilização de técnicas apropriadas e não apreensão de conhecimentos de processos interdependentes são os principais responsáveis pela degradação ambiental

O solo pode ser considerado um recurso básico de uma nação e não renovável. Uma vez perdido, sua reposição torna-se impossível em um curto periodo de tempo (LAL, 1.990).

No Brasil os solos são bastante importantes, visto que a agricultura desempenha papel significativo para a economia do país. Entretanto, os solos do País vêm sofrendo sérios problemas provocados pela erosão, dentre os quais pode-se citar a perda da camada agricultável; a diminuição da produção e a exaustão completa do solo.
A prática de queimadas, criação de gado nos campos, a exploração mineral sem técnicas adequadas e o desmatamento são fatores desencadeadores de intensos fenômenos erosivos, sendo este último o maior catalisador para o desenvolvimento da erosão. O solo sem cobertura vegetal estará exposto completamente à ação dos agentes desencadeadores deste processo.

A pesquisa tratou da erosão do solo na Sub-bacia do Córrego dos Macacos. A referida área está compreendida entre as coordenadas geográficas de $18^{\circ} 59^{\prime}$ a $19^{\circ} 02^{\prime}$ de Latitude Sul, e entre $48^{\circ} 23^{\prime}$ a $48^{\circ} 35^{\prime}$ Longitude Oeste de Greenwich.

$\mathrm{Na}$ Sub-bacia do Córrego dos Macacos ocorrem intensos processos erosivos. Várias boçorocas se desenvolveram na área da referida bacia, enquanto que em áreas adjacentes, sob condições semelhantes de clima, materiais inconsolidados e relevonão apresentam a mesma intensidade de erosão.

A pesquisa teve como objetivo principal estudar os processos responsáveis pela erosão acelerada do solo e problemas ambientais na área de estudo, com prioridade para determinação da erodibilidade a partir de ensaios "in situ" e de laboratório. 


\section{ASPECTOS FISICOS REGIONAIS E LOCAIS}

\section{Clima}

A região do Triângulo Mineiro possui um clima tipicamente tropical, apresentando duas estações bem definidas: uma seca que vai de março a outubro, e outra chuvosa que se estende de novembro a fevereiro.

DEL GROSSI (1.993), caracteriza o clima da região como tipo mesotérmico ou $\mathrm{CWa}$, segundo a classificação de Köppen.

No inverno, a temperatura média mensal atinge cerca de $18^{\circ} \mathrm{C}$ e a precipitação pluviométrica do mês mais seco fica em torno de $60 \mathrm{~mm}$. O clima é frio e seco nesta época do ano. Durante o verão, as temperaturas médias são superiores a $22^{\circ} \mathrm{C}$, raramente atingindo $24^{\circ} \mathrm{C}$. O clima nessa época é quente e úmido. As temperaturas médias anuais, na região, variam entre 20 e $22^{\circ} \mathrm{C}$.

\section{Geologia}

A Bacia Sedimentar do Paraná no Triângulo Mineiro é representada pelas unidades geológicas de idade Mesozóica: arenito da Formação Botucatu, basaltos da Formação Serra Geral e as rochas do Grupo Bauru.

Os arenitos da Formação Botucatu estão melhor representados entre as cidades de Sacramento e Conquista, tendo pouca expressão no Município de Uberlândia, onde ocorrem sob a forma de corpos lenticulares, mapeáveis em escala de 1:100.000. Os afloramentos dessa formação estão próximos às margens do rio Araguari, assentados diretamente sobre o embasamento cristalino do Grupo Araxá e recobertos pelas rochas vulcânicas da Formação Serra Geral.

A Formação Serra Geral é caracterizada pelas rochas efusivas de natureza básica e pequenas lentes de arenitos intercalados aos derrames. No Triângulo Mineiro grande parte das rochas da Formação está recoberta por lotologias mais recentes do Grupo Bauru e sedimentos cenozóicos, porém, as exposições dão-se nos vales dos cursos d'água.

No Município de Uberlândia, os basaltos da Formação Serra Geral afloram ao longo dos vales dos rios Araguari, Uberabinha, Tijuco e Douradinho, onde as camadas sobrejacentes foram desgastadas pela ação fluvial.

O Grupo Bauru está representado na região do Triângulo Mineiro pelas Formações Adamantina, Uberaba e Marilia, sendo que esta última fecha a fase de deposição na Bacia Sedimentar do Paraná.

No Município de Uberlândia, a Formação Marilia é a unidade que apresenta ampla distribuiçào espacial. Acha-se limitada a sudeste pelos rios Araguari e Bom Jardim. esténdendo-se a sul. em direção ao Municipio de Uberaba, e para norte passando por Uberlândia, seguindo em direção aos distritos de Martinésia e Cruzeiro dos Peixotos, a oeste rumo aos Municípios de Monte Alegre de Minas e Tupaciguara. Encontra-se assentada sobre os basaltos da Formação Serra Geral.

Os sedimentos de idade Cenozóica recobrem quase toda a extensão do Município de Uberlândia, capeando as rochas mais antigas e ocupando todos os niveis topográficos, desde as áreas de chapadas até às vertentes dos vales fluviais (NISHIYAMA, 1.989).

\section{Geomorfologia}

A região do Triângulo Mineiro faz parte de um conjunto geomorfológico denominado por AB'SABER (1.972) como Chapadões Tropicais do Brasil Central, e pelo RADAM (1.983) como Planaltos e Chapadas da Bacia Sedimentar do Paraná.

BACCARO (1.989) distingue no Município de Uberlândia três unidades geomorfológicas: área de relevo dissecado, área de relevo intensamente dissecado e área de topo plano. A primeira compreende a faixa com topos aplainados entre $700 \mathrm{e}$ 900 metros. As vertentes são suaves, recobertas pelo cerrado, interrompidas em muitos locais pela laterita, facilitando o surgimento do lençol freático. Em algumas porções do rio Tijuco e Douradinho, têm expressiva planície aluvionar com extensas áreas de solos hidromórficos e meandros. Neste compartimento os processos erosivos manifestam-se de forma mais intensa, abrangendo as áreas das bacias do rio Douradinho, dos Córregos Babilônia, Panga e Macacos, e do ribeirão Estiva. a segunda exibe topos aplainados e alongados, vertentes abruptas e vales profundos. Os topos estendem-se em formas de espigões entre as sub-bacias afluentes do rio Araguari e Uberabinha. Aparecem, também, algumas rampas coluviais, com solos férteis originados do material detrítico da alteração do basalto. A terceira apresenta superficies amplas e planas e vales muito espaçados entre si. Mostra uma baixa densidade de drenagem, vertentes com declividades entre 3 e $5^{\circ}$, sustentadas pelo arenito da Formação Marilia e recoberta por sedimentos do Cenozóico.

Solos

Segundo o Projeto RADAM (1.983), na região do Triângulo Mineiro estão presentes os seguintes tipos de solos: Latossolo Vermelho-Escuro álico e distrófico; Latossolo Vermelho-Amarelo álico e distrófico; Latossolo Roxo distrófico e eutrófico; 
Terra Roxa Estruturada eutrófica: Podzólico Vermelho-Amarelo distrófico e eutrófico; Areia Quartzosa álica; Cambissolo álico e distrófico; e Glei Húmico e pouco Húmico álico e distrófico.

$\mathrm{Na}$ área do Município de Uberlândia são predominantes os solos do tipo Latossolo VermelhoEscuro álico e distrófico; Latossolo Vermelhoamarelo eutrófico; Latossolo Roxo distrófico e eutrófico; Glei Húmico e Pouco Húmico álico e distrófico; e Areia Quartzosa álica.

$\mathrm{Na}$ área de estudo, Sub-bacia do Córrego dos Macacos, estão presentes os Latossolos VermelhoAmarelo, Latossolo Vermelho-Escuro, e os Solos Hidromórficos. Com exceção dos hidromórficos, os demais são bastante profundos e bem drenados, apresentando homogeinidade de cor e textura ao longo do perfil vertical.

\section{Vegetação}

A vegetação natural característica do Municipio de Uberlândia é o cerrado. De um modo geral, essa vegetação (sentido restrito) é constituida por árvores de médio porte, distribuídas entre arbustos e um estrato herbáceo-graminoso denso. Os tipos arbóreos possuem, geralmente, formas tortuosas, com folhas coriáceas e caules e ramos revestidos de expessa camada de súber.

$\mathrm{Na}$ sub-bacia do Córrego dos Macacos a vegetação natural (cerrado), foi substituida pelas pastagens, restando apenas algumas áreas isoladas (capões).

No fundo do vale e nas vertentes da sub-bacia, tem-se a presença de uma vegetação herbáceograminosa, conhecida por campo úmido. É comum encontrar associada a esta vegetação uma espécie de porte arbóreo, o buriti (Mauritia Vinicula) que caracteriza as veredas da Região dos Cerrados do Brasil Central. Os buritis não ocorrem somente no fundo dos vales, mas também em áreas úmidas de encostas.

São encontradas ainda, na área de estudo, algumas manchas de mata galeria ou de encosta, que acompanham os vales da sub-bacia.

\section{MATERIAIS E MÉTODOS}

Em um primeiro momento foram realizados levantamentos de informações pré-existentes (bibliograficas e mapas) acerca do tema pesquisado e produção de informações. Utilizou-se cartas topográficas do Ministério do Exército (1.982), em escala 1:25.000 para confecção da base cartográfica, tendo sido apresentadas sobre esta as seguintes informações do meio fisco: classes de declividade; geomorgologia e materiais inconsolidados. As informaçōes foram obtidas mediante a interpretação de fotografias aéreas em escala de 1:25.000 do IBCGERCA

Foram realizados vários trabalhos de campo, sendo que o preliminar foi para reconhecimento da área em estudo, levantamento de aspectos referentes ao tema em questão e averiguação da fotointerpretação.Nos trabalhos de campo seguintes, foram coletadas amostras deformadas e indeformadas (cilindro) e realizados ensaios de infiltração na área de estudo. outros aspectos da área também foram levantados, tais como: formas de ocupação da área, profundidade do substrato rochoso, profundidade do nivel d'água. as amostras coletadas foram ensaiadas om afinidade de se obter a distribuição textural; a massa específica aparente natural; e o índice de vazios dos solos daquela área. Todas as informações obtidas a partir de trabalhos de fotointerpretação, de campo e de ensaios de laboratório foram representados em mapas, cartas e gráficos e tabelas.

\section{RESULTADOS OBTIDOS}

A área de estudo apresenta duas feições distintas de relevo: formas abruptas de vertentes ao longo do canal principal e dos afluentes e topos planos nos divisores de águas entre as bacias. As formas abruptas dão origem à feições escarpadas com desnivel máximo em torno de $50 \mathrm{~m}$. Ocupam as porções de baixa e média encosta, com declividades quase sempre acima de $100 \%$. O desenvolvimento de feições escarpadas são comuns em litologias da Formação Marilia que apresentam maior resistência aos processos erosivos atuantes nas vertentes fluviais, principalmente os arenitos e conglomerados com cimentação carbonática e lentes de calcário. Sobre 0 segmento que se estende desde a base das escarpas, até o canal fluvial, verifica-se o desenvolvimento de uma superficie de perfil côncavo e inclinação moderada a alta, em torno de 8 a $15 \%$. Nesse local acumulam-se materiais provenientes das porções superiores, formando ali os depósitos coluviais Desenvolve-se uma densidade de drenagem que varia entre baixa e média, predominando 0 padrão dendrítico

Os processos erosivos de uma maneira geral são dominantes em toda a área da sub-bacia do Córrego dos Macacos, principalmente nas suas porções escarpadas, fazendo com que o substrato rochoso fique muito próximo à superficie do terreno. Entretanto, os resultados dos processos erosivos mais visíveis ocorrem na porção imediatamente inferior $e$ superior à faixa escarpada. $\mathrm{Na}$ porção inferior, a erosão, sob as formas de ravinas e boçorocas, atinge principalmente os depósitos de colúvio. 
Sobre a quebra positiva que delimita o topo da camada resistente. também se desenvohe formas de erosão acelerada (boçoroca), sobretudo no local onde o relevo apresenta-se com perfil convexo e curvas de nível côncavas coletoras, conforme os modelos de formas de encostas apresentadas por TROEH, 1.965, apud RODRIGUES 1.982.

Foram identificados na área de estudo os seguintes tipos de materiais inconsolidados: residuais litólicos; depósitos coluviais; e solos hidromórficos e/ou orgânicos. Foram identificados na área estudada duas gerações de depósitos coluviais, identificados como colúvio 1 e colúvio 2 . Nas porções topograficamente inferiores das vertentes fluviais acham-se presentes depósitos de colúvio 2, texturalmente mais argiloso do que o colúvio 1 , ocupando as porções entre solos hidromórficos e/ou orgânicos do fundo de vale e faixa de residuais litólicos da Formação Marília. Em áreas de topo, sob condições de declividade moderada, estes residuais encontram-se recobertos por colúvios arenosos.

Os residuais litólicos acham presentes nas porções mais declivosas das vertentes fluviais, tendo como substrato rochoso, os arenitos e conglomerados fortemente cimentados. Em razão dessas condições desenvolvem pequenas espessuras de cobertura inconsolidada (litólicos)

De um modo geral, os materiais presentes na sub-bacia do Córrego dos Macacos possuem textura bastante arenosa. Observar Tabela 01.

TABELA 01 - RESULTADOS DE ANÁLISE GRANULOMÉTRICA CONJUNTA

\begin{tabular}{|l|c|c|c|c|c|}
\hline Material & Am.1 & Am 2 & Am 3 & Am. 4 & Am. 5 \\
& Col.1 & Col. 1 & Col. 2 & Col. 2 & Col. 1 \\
\hline Argila & 19 & 19,5 & 20,5 & 27,5 & 18,5 \\
Silte & 06 & 6,5 & 11,5 & 4,5 & 06 \\
A Fina & 51 & 47,5 & 35 & 44 & 53 \\
A Média & 23 & 5,0 & 31 & 23 & 22,5 \\
A Grossa & 01 & 1,5 & 02 & 01 & 0 \\
\hline Total (\%) & 100 & $100 \%$ & $100 \%$ & $100 \%$ & $100 \%$ \\
\hline
\end{tabular}

Observação: Am - Amostra

$$
\text { Col - Colúvio }
$$

São identificadas na referida área 18 boçorocas. A maioria destas desenvolveram-se em áreas de materiais colúviais, distribuídos da seguinte forma: nove boçorocas no colúvio arenoso 1 e nove no colúvio arenoso 2. Nas áreas de topo os materiais de alteração da Formação Marilia, podendo ser observadas apenas nos taludes de erosão junto às boçorocas. Nesse local a espessura desses materiais varia desde algumas dezenas de centímetros onde 0 processo erosivo teve início, a 6 metros nas porções de cabeceira. As ravinas desenvolveram-se principalmente em áreas de colúvio arenoso 2 . São encontradas também em áreas de residuais litólicos, porém em menor frequeência. Nas áreas de colúvio arenoso 1, elas aparecem em proporção bem menor do que nas áreas citadas anteriórmente em razão da baixa declividade. $\mathrm{Na}$ maioria das vezes os processos erosivos têm início nas rupturas de declive, sobretudo nas positivas, as quais determinam formas convexas de encostas.

A profundidade do leçol subsuperficial verificadano interior das boçorocas é em torno de 10 metros.

Foram estabelecidas para a área de estudo, cinco classes de declividade, sendo a primeira menor que $2 \%$, a segunda de 2 a $5 \%$, a terceira de 5 a $10 \%$, a quarta de 10 a $20 \%$, e a quinta maior que $20 \%$. Nas áreas onde desenvolvem os residuais litólicos do Marilia, as declividades são mais acentuadas, isto é, superiores a $20 \%$, podendo, em alguns locais, superar o valor de $100 \%$ de inclinação. Nas áreas de depósito de colúvio 2, as declividades são moderadas, predominando a classe de 5 a $10 \%$. Nas áreas de colúvio arenoso 1 (áreas de topo), os valores são baixos, sendo mais frequente a classe de 2 a $5 \%$, e mais raramente inferior a $2 \%$. Nas áreas de solos hidromórficos de encostas, os valores de declividades encontrados são elevados, predominando a classe de 10 a $20 \%$, porém, valores no intervalo de 5 a $10 \%$ também são observados.

Ao se determinar (em laboratório) o teor de umidade das amostras coletadas no campo, observouse que a umidade antes da infiltração variava de 4 a $12 \%$; a umidade logo após a infiltração variou de 14 a $27,5 \%$; e a umidade duas horas após a infiltração variou de 10 a $22 \%$.

Nos trabalhos de campo foram retiradas não somente amostras deformadas, mas também amostras indeformadas (cilindro), sendo possivel calcular os índices de vazios do solo. As amostras coletadas (sete pontos distintos) em cilindros apresentaram elevado índice de vazios, variando no intervalo de 1,69 a 1,98.

As análises texturais obtidas pelos ensaios de granulometria conjunta mostram que o teor de argila varia de 18,5 a $20,5 \%$, sendo esta percentagem superior apenas num ponto, atingindo $27,5 \%$ nas áreas de colúvio 2 . Foram calculadas ainda a percentagem de silte, que variou de 4,5 a $6,5 \%$, porém próximo a uma boçoroca esta percentagem chegou a $11,5 \%$. Quanto à percentagem de areia, determinada no mesmo ensaio, variou entre 68 e $75,5 \%$, predominando a areia fina.

Foram realizados cinco ensaios de infiltração, em cinco pontos distintos. Com exceção do ponto 3, realizado em área de mata degradada, os demais demais foram em áreas de pastagem.. O ensaio do ponto 1 foi realizado em área de colúvio 1 . A umidade do solo desta área apresenta-se relativamente alta $(4,84$ a $20 \mathrm{~cm}$ e 8,02 a $80 \mathrm{~cm}$ de profundidade), se comparada com as dos pontos 03 e 04 . A 
capacidade de infiltração de água encontrada foi muito baixa ( $50 \mathrm{~mm}$ de infiltração/hora) em relação aos demais pontos, embora tem-se nesta área o predomínio da fração areia (81\%). O ensaio do ponto 2 também foi realizado em área de colúvio 1 . A umidade do solo é baixa $(4,84$ a $20 \mathrm{~cm}$ e 6,92 a $80 \mathrm{~cm}$ de profundidade) e a capacidade de infiltração apresentou valores intermediários entre os pontos 05 e 04 . O ensaio do ponto 3 foi realizado em área de colúvio 2 , ao lado de uma boçoroca. O solo deste ponto foi 0 que apresentou maior capacidade de infiltração. Além disso, foi o segundo em teor de umidade $(7,21$ a $20 \mathrm{~cm}$ e 9,91 a $80 \mathrm{~cm}$ de profundidade). A distribuição textural dos materiais inconsolidados deste ponto dá-se da seguinte maneira: argila, 20,5\%; silte, 11,5\%; e área, $68 \%$. O ensaio do ponto 4 também foi realizado em área de colúvio 2.0 solo deste ponto foi o que apresentou maior umidade $(7,57$ a $20 \mathrm{~cm} \mathrm{e} 10,41$ a $80 \mathrm{~cm}$ de profundidade). Sua capacidade de infiltração é baixa $(130 \mathrm{~mm} / \mathrm{hora}$ de infiltração).Em relação aos pontos 02,03 e 05. Nesta área, os materiais inconsolidados distribuem-se da seguinte maneira: $27,5 \%$ de argila; $4,5 \%$ de silte; e $68 \%$ de areia. O ensaio do ponto 5 foi realizado em área de colúvio 1, à aproximadamente 100 metros de uma boçoroca. $O$ solo desta área foi o que apresentou menor umidade $(4,91$ a $20 \mathrm{~cm}$ e 5,88 a $80 \mathrm{~cm}$ de profundidade). Em relação aos demais pontos, o solo desta área possui alta capacidade de infiltração, porém situando-se abaixo do ponto 3 .

Nos ensaios de infiltração observou-se que de uma modo geral, tanto os materiais do colúvio 1 quanto do 2 apresentaram elevada capacidade de infiltração. Apenas o ponto 1 mostrou-se discrepante em relação aos demais.

\section{CONCLUSÃO}

A sub-bacia do Córrego dos Macacos vem sofrendo intenso desgaste erosivo, tanto em forma de bocorocas como em forma de ravinas.

Vários fatores favoreceram o surgimento destes processos, como por exemplo a textura dos materiais, a declividade e o relevo.

Os materiais inconsolidados da referida área ossuem textura arenosa e são extremamente frágeis à ação mecânica da água, apresentando elevada erodibilidade, altos indices de vazios, embora apresentem elevados valores de infiltração. Encontram-se amplamente distribuidos nas vertentes fluviais, com declividades moderadas, que variam de 5 a $10 \%$.

A análise dos resultados de infiltração de água $\mathrm{e}$ de textura, parece indicar que a entrada de água no solo e a predominância da fração areia nos materiais inconsolidados na área da bacia do Córrego dos
Macacos. não são fatores únicos a influenciar 0 desenvolvimento de formas de erosão acelerada (boçoroca). A elevada capacidade de infiltração na maioria dos pontos ensaiados, especialmente o ponto 3, ao lado de uma grande boçoroca, mostra que, mesmo sob essa condição, a erosão acelerada se desenvolve.

Uma característica particular da área é a presença de uma camada resistente e de baixa permeabilidade, em nível de média a alta encosta. Essa camada é responsável pelo desenvolvimento de um perfil de encosta abrupto na faixa de sua ocorrência, e ao mesmo tempo, responsável pela retenção da água de infiltração (da chuva) em níveis superficiais do terreno. A grande maioria das erosões (boçoroca e ravinas) tem origem nessa faixa de maior declividade e úmida, possivelmente onde são gerados os escoamentos superficiais em razão de não ocorrer infiltração de água nesse local.

A configuração do relevo nas porções situadas topograficamente acima dessa camada de baixa permeabilidade, também é favorável à concentração das águas pluviais de escoamento superficial (encostas convexas e curvas de nível côncavas).

A avaliação que se chega para a área estudada, é a de que vários processos e características do meio físico atuam de forma interdependente, culminando nas formas erosivas. Dentre estas podemos citar: chuvas concentradas (elevada erosividade), elevada eroctibilidade (camadas coluviais e residuais do Marília); presença de nível de água aflorante em um nível da vertente fluvial; configuração das encostas (perfil côncavo e curvas de nível côncavas); a ação antrópica (remoção da cobertura vegetal, concentração das águas pluviais, abertura de valas e outras).

Atualmente as boçorocas vêm sendo utilizadas para a deposição đe resíduos sólidos do município, constituindo-se em um dos mais graves problemas ambientais. A sub-bacia do Córrego dos Macacos é um dos tributários de uma importante bacia hidrográfica da região do Triângulo Mineiro (bacia do rio Tijuco). Todo chorume produzido tende, em princípio, se escoar para as drenagens, atingindo desse modo, os principais rios da bacia. Por outro lado, parte do liquido produzido pode se infiltrar no solo e atingir o nível freático.

Este tipo de ocupação da área, tem levado à contaminação da água subsuperficial e profunda, pois além dos materiais possuírem textura bastante arenosa, o lençol subsuperficial está à pequena profundidade cerca de 10 metros.

A tentativa de contenção da erosão, tem contribuído para que a situação agrave ainda mais uma vez que expõe o residual da Formação Marilia 
que é menos resistente à erosão do que os materiais do depósito de colúvio 1.

A partir dos dados de textura. infiltração da água no solo, forma de relevo, presença de camada mais resistente e menos permeável da Formação Marília e a forma de ocupação, pode-se afirmar que $o$ desenvolvimento das boçorocas e ravinas na área do Córrego dos Macacos é resultado da interação de todos os fatores mencionados.

A área deve ser ocupada com cuidados, respeitando as características locais (declividade, textura, formas de relevo e presença do lençol a pequena profundidade).

A reabilitação da área não pode ser implementada de maneira aleatória, sem estudos prévios, pois se isto acontecer, corre-se o risco de piorar a situação das boçorocas ou mesmo iniciar novas erosões, como já vem ocorrendo nas cabeceiras das boçorocas.

\section{REFERÊNCIAS BIBLIOGRÁFICAS}

AB'SABER, A.N. Contribuição à geomorfologia da área dos cerrados. In: Simpósio Sobre o Cerrado. São Paulo: EDUSP. p. 97-105, 1.972.

BACCARO, C.A.D. Estudo dos processos geomorfológicos de escoamento pluvial em área de cerrado - Uberlândia - MG. Tese de Doutoramento. USP. São Paulo, 1.990. ,C.A.D. Unidades geomorfológicas do município de Uberlândia - MG. Sociedade e Natureza. Uberlândia, $\mathrm{n}^{0}$, ano 1 , p. 13-22, junho.1.989.

BIGARELA, J.J. \& MAZUCHOWSKI, J.Z. Visão integrada da problemática da erosão. ABGE e ADEA. Maringá, 1.985. 332p.

BORGES, K.M.R. Erosão acelerada (boçorocas) na área urbana de Uberlândia: causas e fatores responsáveis pelo seu desenvolvimento. Relatório CNPq. 1.993.

BRASIL. Ministério das Minas e Energias. Levantamento de recursos naturais. Rio de Janeiro. V. 31. 1.983 (Projeto Radam Brasil)

CAMARGO, O.A.; MONIZ, A.C.; JORGE, J.A.; VALADARES, J.A.S. Métodos de análise química, mineralógica e física dos solos do Instituto Agronômico de Campinas. São Paulo, 1.986. p.66-69 e 83-86.

CONTROLE de erosão: bases conceituais e técnicas; diretrizes para planejamento urbano e regional; orientações para controle de boçorocas urbanas. DAEE/IPT, São Paulo. 1.989.

DEL GROSSI, Suely Regina. A dinâmica climática atual de Uberlândia e suas implicações geomorfológicas. Sociedade e Natureza.
Lberlândia. $\mathrm{n}^{\text {cs }} 9$ e 10, ano 5. p.120, jan/dez. 1.993.

FURLANI, G.M. Estudo geomorfológico das boçorocas de Casa Branca, São Paulo. Dissertação de Mestrado. Departamento de Geografia da FFCLH - USP. 1.980. 379p. .

HEMPEL, Carl G. Filosofia da ciência natural. Trad. Plínio Sussekind Rocha. 2ed. Rio de Janeiro; Universidade Federal de Guanabara, 1.974.142p.

HIDALGO, P. Fatores del deterioro de los recursos naturales renovables. Charla. $n^{0} 1$. C.I.D.I.A.T. Mérida. 1.985. p.01

$\mathrm{LAL}, \mathrm{R}$. Soil erosion in the tropics - principles and manegement. New York. McGraw-Hill.1.990. $580 \mathrm{p}$.

LIMA, Samuel do Carmo. As veredas do ribeirão Panga no Triângulo Mineiro e a evolução da paisagem. Tese de Doutoramento. USP. 1.996.

MILLER, W.P; BAHARUDDIN, MK. Particle size of interrill-erod sediments from highly wethered soils. Soil Sci. Am. J. V.51, p.16101615. 1.987.

NISHIYAMA, Luiz. Geologia do município de Uberlândia e áreas adjacentes.Sociedade e Natureza. Uberlândia, $\mathrm{n}^{0} 1$, ano 1 , p.09-15, junho.1.989.

,L.Mapeamento geotécnico preliminar da quadrícula de São Carlos-SP. Dissertação de Mestrado. Escola de Engenharia de São Carlos USP. São Carlos. 1.991. 228p.

L. Erosão do solo: uma visão integrada dos fatores e processos que condicionam o seu desenvolvimento. Escola de Engenharia de São Carlos - USP. 1.995

NOGAMI, J.S.; \& VILLIBOR, D.F. Soil characterization of mapping units for highway purposes in a tropical área. Bul. Of the International od Engineering Geology. krefeld. Alemanha. ${ }^{0} 191.979$.

OKA-FIORI, C.; \& SOARES, P.C. Aspectos evolutivos das boçorocas. Notícias Geomorfológicas. PUC, v.13,n $32,114-124$, dez. 1.976.

RODRIGUES, J.E. Estudo de fenômenos erosivos acelerados. Tese de Doutoramento. Escola de Engenharia de São Carlos - USP. São Carlos. 1.982.

VIEIRA, N.M. Estudo geomorfológico das boçorocas de Franca, SP. Tese de Doutoramento. FFCL. Franca. 1.973.

VILAR, O.M.; \& PRANDI, E.C. Erosão dos solos. in: CINTRA, J.C.A.; ALBIERO, J.H. (Eds) Solos do Interior de São Paulo. São Carlos. Cap.7, p. 177206. 1.993 . 